\title{
Influence of Respiratory Exacerbations on Lung Function Variables and Nutritional Status in CF Patients
}

\author{
H. J. NEIJENS, ${ }^{1}$ E. J. DUIVERMAN, ${ }^{1}$ K. F. KERREBIJN ${ }^{1}$ \\ and M. SINAASAPPEL ${ }^{2}$ \\ From the Department of Pediatrics, Subdepartment of ${ }^{1}$ Respiratory Diseases and of ${ }^{2}$ Gastroenterology \\ Erasmus University and University Hospital Rotterdam/Sophia Children's Hospital, \\ Gordelweg 160, 3038 GE Rotterdam. The Netherlands
}

The interaction between the severity of respiratory abnormalities and the nutritional status in cystic fibrosis (CF) patients is not fully elucidated as yet. Several studies indicate that a decline in lung function and a diminishment in the nutritional status are associated $(1,2)$. The nutritional status of patients who have relatively low lung function values turns out to have a disturbed nutritional status and vice versa. This association does, however, not resolve the problem which of both is the cause and which the result. It might well be that each of both, a decline in respiratory function or a decrease in the nutritional status, might affect the other one. Such a mutual interaction may easily lead to a viscious circle. Respiratory infections may deteriorate the nutritional status, which in turn may enhance the chance on infections, while break down of pulmonary tissue is the result. It is important to recognize these interactions and to counteract such a viscious circle as much as possible.

In this study the relationship and interaction between respiratory infections and nutritional status are analysed in two ways. Firstly, we have compared lung function variables and either body weight or height in a group of CF patients who are in steady state (group A, see methods). Secondly, we have compared the change in lung function variables and body weight as well as several other factors in the course of a respiratory exacerbation. The aim is to study the influence of the occurrence or increase in respiratory infections on the nutritional variables. These measurements are performed without and with an additional feeding regime during the night, in order to see if a high caloric supplementation can prevent a decline in nutritional status during the infection.

\section{METHODS}

\section{Patients}

60 patients with CF, are studied (group A). Their selection criteria are: (a) Sweat chloride concentration $>80 \mathrm{mmol} \cdot \mathrm{I}^{\prime}$ and clinical symptoms which are in accordance with CF. $(b)$ Able to perform reliable lung function tests. Their mean age is 14.5 years, with a range from 8 to 20 years. 12 patients, originally belonging to group $\mathrm{A}$, were followed along an exacerbation, which necessitated treatment with intravenous antibiotics (group B).

\section{Measurements}

In group $\mathrm{A}$ the following variables are registered: $(a)$ Body weight and height. Height is measured according to Tanner (3). Weight is expressed as a percentage of ideal body weight for height (weight corrected for height). Height is given as standard deviation score reflecting the difference with the normal value for age. (b) The forced vital capacity (FVC) and the forced expiratory volume in $1 \mathrm{sec}$ $\left(F E V_{1}\right)$ from a flow-volume reading with a time signal (Finivess). The best of three adequate measurements is selected as the result.

In group $B$ the following variables are registered during an exacerbation on days $1,4,8$ and 16 after the beginning of antibiotic treatment: $(a)$ body weight and height according to the measurements of group $\mathrm{A}$ and $(b)$ FVC and $\mathrm{FEV}_{\mathrm{t}}$ according to the measurements of group A. 

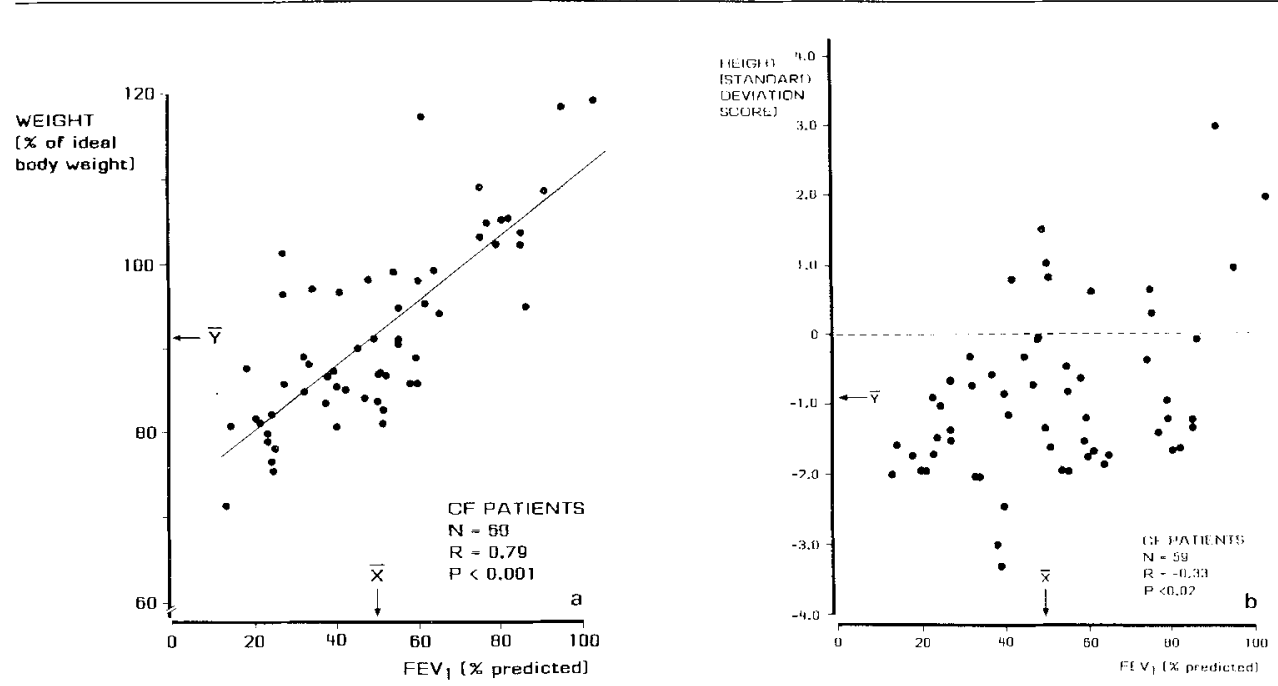

Fig. 1. (a) The relationship between body weight and lung function, expressed as the forced expiratory volume in $1 \mathrm{sec}\left(\mathrm{FEV}_{1}\right)$, is shown in a group of $60 \mathrm{CF}$ patients. The mean values for each of both variables are indicated. The relationship is significant and indicated by the regression line. (b) The relationship is shown between height, expressed in standard deviation score of the normal value for age, and the lung function, reflected by the $\mathrm{FEV}_{1}$, in a group of $59 \mathrm{CF}$ patients. The mean values for each of both variables are indicated.

\section{RESULTS}

Fig. $1 a$ shows that a statistically significant relationship exists between $\mathrm{FEV}_{1}$ and weight corrected for height in patients in a steady state (group A) $(p<0.001)$. The mean FEV 1 is $42 \%$ of expected, while the mean weight corrected for height is $91.7 \%$.

Height, expressed as standard deviation scores (SDS) is given in relation to the FEV 1 in Fig. $1 b$. Height tends to be relatively low as $\mathrm{FEV}_{1}$ is decreaed and vice versa. Although their relationship is significant, a wide scatter is found.

Fig. 2 shows the changes in $\mathrm{FEV}_{1}$ (graph a) and in weight (graph b) during an infectious exacerbation and its antibiotic treatment (observed in group B). On the first day of treatment the mean decrease in $\mathrm{FEV}_{1}$ was $13.0 \pm 2.9 \%$ of the steady state value. In the course of the treatment the FEV, gradually increases till $-10.0 \pm 2.6,-3.9 \pm 1.7$ and $-0.6 \pm 1.7 \%$ of the value before the exacerbation at the 4 th, the 8 th and the 16 th day respectively. The $\mathrm{FEV}_{1}$ has reached its baseline value after 16 days in most patients. Weight on the 1 st day of treatment is decreased $1.3 \pm 0.12 \mathrm{~kg}$ below the value at steady state. Weight increase till $-1.1 \pm 0.2,-0.5 \pm 0.2$ and $-0.1 \pm 1.2 \mathrm{~kg}$ below steady state at days 4,8 and 16 respectively. Weight increment approximately parallels improvement of $\mathrm{FEV}_{1}$. The relationship between the fall in $\mathrm{FEV}_{1}$ and in body weight in the progression of an infection is weak $(R=0.42,<0.05)$.

The change in weight during an infectious exacerbation in a patient either on a usual diet or receiving hyperalimentation (extra \pm 1000 calories) by a gastric drip during the night is shown in Fig. 3. A decrease in body weight is clearly diminished when hyperalimentation is given in contrast to what occurs on a usual diet.

\section{DISCUSSION}

A close association between body weight, as a measure of the nutritional status, and the FEV, reflecting lung function, is found in this and other studies $(1,2,4)$. This can be 

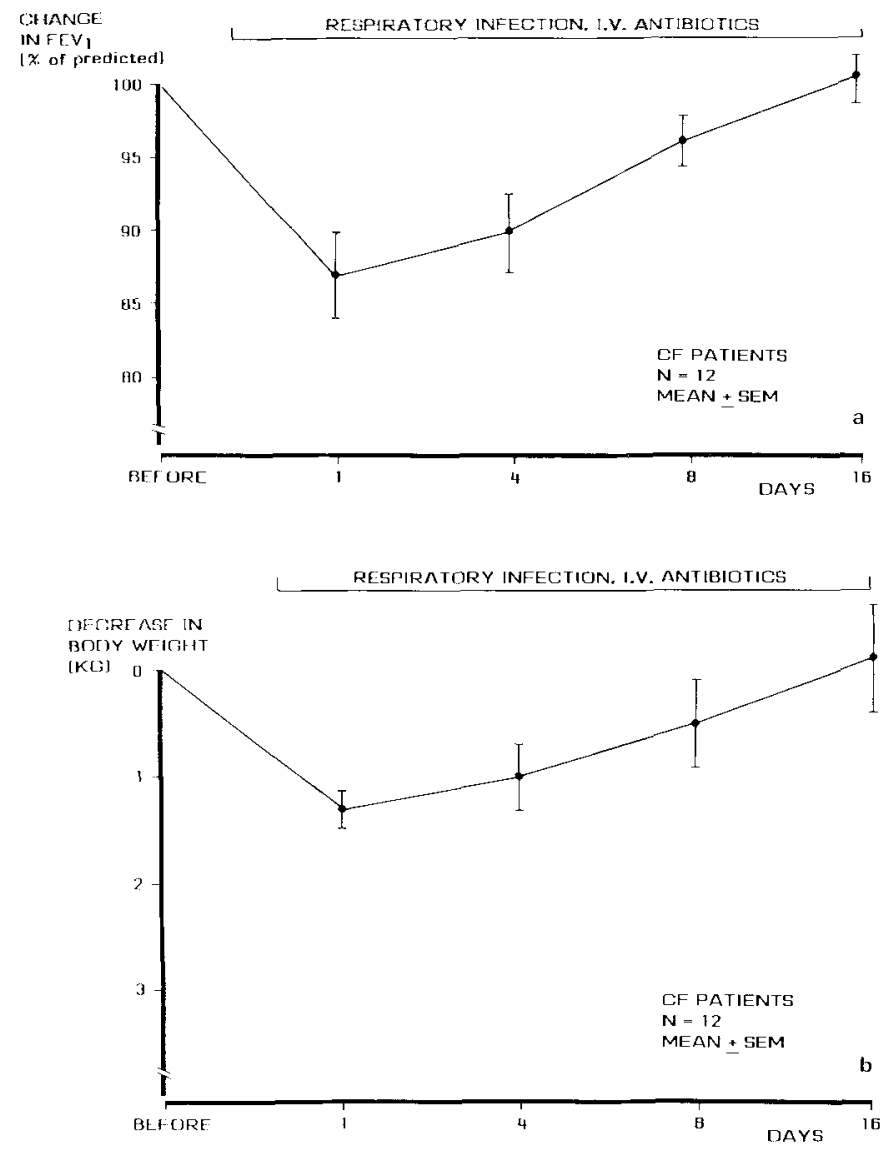

Fig. $2 a$ and $b$. The mean change in lung function reflected by the FEV (graph a) and in body weight (graph b) in $12 \mathrm{CF}$ patients is shown in the course of an infectious exacerbation.

observed on longterm basis (Fig. 1) as well as during temporary exacerbations (Fig. 2). The relationship on longterm basis is also present in patients with emphysema who show in the same manner a correlation between the degree of air flow obstruction and somatic depletion $(5,6)$. This observation further strengthens the relationship between a decline in lung function and nutritional status, because in emphysema an influence of hepatic or gastro-intestinal disturbances is not operative. Additionally, an infectious exacerbation is associated with an acute weight loss, which is mostly completely reversible. A weight loss is not exclusive for CF patients, but widely recognised in pneumonia or tuberculosis.

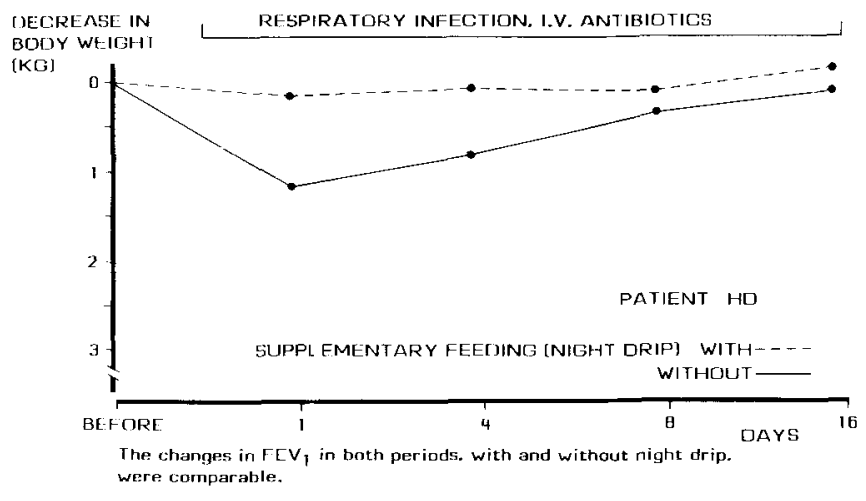

Fig. 3. The change in body weight in the course of an infectious exacerbation in a CF patient as it occurred without and with an extra feeding by night drip ( 1000 cal). The decrease and recovery of the FEV are approximately the same on both occasions. 
Thus, a progressive loss in lung function and a temporary deterioration due to an acute infection may be monitored by repeated measurements of lung function and of weight.

A practical consequence of these observations is the possibility to recognize an exacerbation by a fall in lung function and weight, besides the use of other parameters. Also the recovery during treatment can be monitored by an increase in lung function and weight. We make a plea to use repeated measurements of lung function and weight in the monitoring of the detection and the course of exacerbations in CF patients. The duration and intensity of antibiotic treatment can be adapted taking these measurements into account.

An explanation for the weight loss might be anorexia and catabolism. The drop in weight is variable between patients, partly because of the "sensitivity" of the metabolic interactions and of the appetite. Hence, it is not surprising that only a weak correlation exists in our patients between the fall in body weight and $F E V_{1}$ as caused by an infection. This short term effect seems to be largely reversible and can be prevented by additional caloric intake (Fig. 3). This was also observed by Berry et al. (7) and Bradley et al. (8). Hence a temporary relative shortness of nutritional components is probably the case. Based on these observations it can be assumed that long-lasting or recurrent respiratory infections will progressively deteriorate the nutritional status. Consequently, the use of hyperalimentation may have value for the optimalisation of the nutritional status, especially during infectious exacerbations. This may be applied by a gastric drip during the night or an intravenous feeding.

Very little, if any, evidence is available to support the possibility that an insufficient nutritional status will enhance the deterioration of the respiratory system. The connective tissue composition of the lung was found to be changed in rats during starvation, but reestablished after refeeding (9). However, the relevance for patients needs to be established.

\section{REFERENCES}

1. Kraemer R, Rudeberg A, Hadorn B, Rossi E. Relative underweight in cystic fibrosis and its prognostic value. Acta Pediatr Scand 1978; 67:33-37.

2. Yassa JC, Prosser R, Dodge JA. Effects of an artificial diet on growth of patients with cystic fibrosis. Arch Dis Childh 1978; 53: 777-83.

3. Tanner JM, Whitehouse RH. Atlas of children's growth: normal variation and growth disorders. London: Academic Press, 1982.

4. Chase HP, Long MA, Lavin MH. Cystic fibrosis and malnutrition. J Pediatr 1979; 95:337-47.

5. Openbrier DR, Irwin MM, Rogers RM, Gottlieb GP, Dasher JH, van Thiel DH, Pennock BE. Nutritional status and lung function in patients with emphysema and chronic bronchitis. Chest $1983 ; 83: 17-22$.

6. Hughes RL. The Jack Spratt connection. Chest 1982; 82:518-19.

7. Berry HK, Kellogg FK, Hunt MM, Ingeberg KL, Richter L, Gutjahr C. Dietary supplement and nutrition in children with cystic fibrosis. Am J Dis Child 1975; 129: 165-71.

8. Bradley JA, Aron ATR, Hill GL. Nocturnal element diet for retarded growth in a patient with cystic fibrosis. Br Med J 1979; 167.

9. Sahebjami H, Margee J. Changes in connective tissue composition of the lung in starvation and refeeding. Am Rev Respir Dis 1983; 128:644-47. 